\title{
12 \\ GESTURES AND SECOND \\ LANGUAGE ACQUISITION
}

\author{
Marianne Gullberg
}

\section{Introduction}

When we speak, we regularly gesture as an integral part of communicating. For example, my colleague just explained how her husband backed into another car this morning (she banged her right fist against her flat left hand). One of the hubcaps came off at the impact and disappeared off down the lane (her right hand traced a circling trajectory off to the right). Throughout, she used two modes of expression to convey meaningful elements of the visual scene described: speech and gesture. This chapter presents an overview of why gestures like these are relevant to the cognitive linguistics of Second Language Acquisition (SLA) and, specifically, what gestures can tell us about the processes of SLA. The chapter focuses on two key aspects: (a) gestures and the developing language system and (b) gestures and learning. It further discusses some implications of an expanded view of language acquisition that takes gestures into account.

The first section gives a brief introduction to gesture studies. It demonstrates how gestures are systematically related to speech and language at multiple levels, and reflect linguistic activities in non-trivial ways. It also outlines the current views on the relationship between gesture, speech, and language, and exemplifies cross-linguistic systematicity and variation in gestural repertoires. The second section illustrates what gestures can contribute to the study of a developing second language (L2)-both to a particular L2 and to the developing L2 system in general. With regard to particular L2s, gestures open new avenues for exploring cross-linguistic influences in that learners' gestures allow us to glean information about L1-L2 interactions at the level of semantic-conceptual representations. With regard to $\mathrm{L} 2$ development generally, evidence of systematically parallel change in gesture and speech at a given point in development allows for the investigation of how communicative and cognitive constraints influence learner varieties. The third section reviews findings that suggest 
that both the perception and production of gestures have learning benefits. The chapter concludes by discussing some implications of these findings for $\mathrm{L} 2$ acquisition, specifically regarding the relationship between underlying representations and surface forms, and the notion of nativelikeness.

\section{An introduction to gestures}

\subsection{The basics}

Gestures are typically defined as symbolic movements related to ongoing talk or to the speaker's expressive intention (cf. Kendon, 2004; McNeill, 1992). This definition excludes functional actions like cutting paper with a pair of scissors, self-regulatory movements such as scratching or playing with strands of hair (Ekman \& Friesen, 1969), and more traditional types of nonverbal behavior like posture, blushing, etc. (cf. Poyatos, 2002). These behaviors are not without communicative relevance but are not typically part of the message the speaker is trying to convey. The definition still includes a wide range of behaviors: movements like the "victory" gesture, movements depicting properties of objects or events (e.g. bringing the extended index and middle finger together repeatedly as if moving the legs of a pair of scissors), movements pointing to real or imagined things, and simple rhythmic movements. All these behaviors are gestures.

Gestures can be described in terms of their formal, structural properties such as the configuration of the articulators (hands, arms, etc.), the place of articulation (gesture space), and the form of the movement (cf. Stokoe, 1980). Gestures also have internal structure. During the preparation phase the hands move into a particular part of gesture space. The stroke is the core of the gesture where the spatial excursion of the limb reaches its maximum. During the retraction phase the hands fall back to a resting position. These three phases can be separated by holds when the hands are temporarily immobile in gesture space before they move on to the next phase. A whole gesture unit can thus consist of a preparation, a pre-stroke hold, a stroke, a post-stroke hold, and a retraction (Kendon, 1972; Kita, Van Gijn, \& Van der Hulst, 1998; Seyfeddinipur, 2006). Gesture phase analysis and the identification of the stroke is crucial to issues of temporal gesture-speech alignment, which in turn underpins the theorizing about the relationship between speech and gesture.

A number of categorization and classification schemes for gestures have been proposed. Many are based on a combination of semiotic and functional distinctions (for an overview, see Kendon, 2004). All systems identify a class of conventionalized, language- and culture-specific gestures that constitute fixed form-meaning pairs with standards of wellformedness. These are often called emblems (Efron, 1941/1972; Ekman 
\& Friesen, 1969), exemplified by the "victory" gesture mentioned. The conventional nature of these gestures is illustrated by the different meanings attributed to the same gesture form. For instance, the "ring" gesture (thumb and index joined in a circular form) alternatively means "OK," "good," "worthless," "money," and "body otifice" depending on where you are in the world. The victory gesture (index and middle finger in a $V$-shaped configuration with palm turned outwards) demonstrates the importance of correct form. The outward orientation of the palm is crucial to distinguish it from a similar insulting British gesture with the palm turned towards the speaker. All schemes also recognize gestures with no formal standards of well-formedness that are instead created on the fly. These movements are labeled simply (speech-associated or co-speech) gestures, or gesticulation. In this class further distinctions are made between representational and rhythmic gestures. These represent, depict, illustrate, or emphasize some aspect of what is being conveyed. A current influential classification scheme fot speech-associated gestures is based on four not mutually exclusive categories where iconic, metaphoric, and deictic gestures constitute representational gestures, and beats are thythmic (McNeill, 1992).

Gestures thus vary on a range of dimensions-sometimes refetred to as Kendon's continua (Kendon, 1988; McNeill, 1992, 2000). They are to varying degrees "language-like," meaning that they are more or less arbitrary, segmentable and combinatorial. Gestures are more or less conventionalized or "lexicalized"; performed with varying degrees of awareness; and are mote or less dependent on accompanying speech. These multiple and gradient properties yield very complex form-function relationships in gestures. Gestures are deeply multi-functional and have both communicative and self-directed, cognitive functions, sometimes simultaneously. Gestures are sensitive to communicative and contextual factors such as visibility between interlocutots (Alibali, Heath, \& Myers, 2001; Bavelas, Chovil, Lawrie, \& Wade, 1992), and the spatial distribution of interlocutors (Özyürek, 2002a). As visuo-spatial phenomena they constitute an important communicative resource for speakers who deliberately draw on them to convey certain aspects of their message (Holler \& Beattie, 2003; Melinger \& Levelt, 2004). Other clearly interactional functions include turn tegulation, feedback eliciting, agreement marking, attention direction (pointing), etc. The self-directed functions are somewhat more controversial but are all related to the relationship between gestures, speech, language, and thought.

\subsection{Gestures, speech, and language}

The link between gesture, speech, and language is evident in a number of ways. First, gestures are mainly a speaker-phenomenon. People typically 
gesture when they speak, not when they are silent. Second, gestures serve linguistic functions. For instance, gestures provide propositional content to many deictic expressions. The referents of expressions like "that one" and "there" in (1) are provided by deictic gestures, marked by square brackets. Without the gestures indicating the item and the location, the utterance would have little meaning. Gestures can also occupy structural slots in an utterance and function as a part of speech ("mixed syntax," Slama-Cazacu, 1976). In (2) a zig-zagging gesture functions as a verb. Gestures also serve as entire speech acts or modify other spoken speech acts (cf. Kendon, 2004). A speaker holding up the fist to the ear with thumb and pinkie extended, as in (3), is performing a speech act, namely promising to telephone.

(1) Put [that one] [there].

(2) She [] down the slidebar.

(3) [].- Sure, call me'at home after five.

The link is also evident in the semantic and temporal co-ordination between the modalities observed at various levels of granularity. Gestures and speech often express the same or closely related meaning at the same time (Kendon, 1972; McNeill, 1992). Temporally, the most meaningful part of a gesture, the stroke, will typically be coordinated with the coexpressive part of speech. The sophisticated temporal alignment can be observed in the detailed adaptation of gesture to speech: the preparation phase of a gesture is timed such that the hand is in place for the stroke to co-occur with the relevant speech element; pre-stroke holds make gestures "wait" for speech (Kita, 1993), and stroke onsets shift depending on changes in speech onset (Levelt, Richardson, \& La Heij, 1985) and contrastive stress (De Ruiter, 1998). Regarding meaning, gestures generally reflect the information selected for expression in speech. For instance, a speaker may perform a gesture with extended index and middle finger doing a cutting movement saying "she cut the tope." The gesture redundantly depicts the cutting event. However, many gestures also express additional but related information to speech, particularly spatial or imagistic information such as size, shape, and directionality (e.g. Beattie $\mathbb{E}$ Shovelton, 2002; Kendon, 2004). If the cutting gesture is performed with the palm facing downwards, this suggests that the rope was vertically oriented, perhaps hanging from the ceiling.

Further, the integration between the modalities is reflected in the parallel development of the modalities in childhood (e.g. Mayberry \& Nicoladis, 2000), the parallel breakdown in disfluency (Seyfeddinipur, 2006), stuttering (Mayberry \& Jaques, 2000), and in aphasia (McNeill, 1985; but see Goodwin, 2000; Lott, 1999 for aphasics' communicative use of some gesture types). 
The tight connection between gesture and speech also extends to reception. Interlocutors or addressees do not only draw on gestures under special circumstances to improve understanding in problematic cases but process gesture and speech information in parallel and as a default. The evidence comes from studies showing that information that has only been present in gesture resurfaces in speech or gesture or both. Moreover, if speech and gesture express conflicting information, the modalities interfere with each other in both directions (Cassell, McNeill, \& McCullough, 1999; Langton, O'Malley, \& Bruce, 1996). Finally, neurocognitive evidence suggests that the brain processes gesture and speech together in similar ways to how it processes speech alone (Kelly, Kravitz, \& Hopkins, 2004; Willems, Özyürek, \& Hagoort, 2005; Wu \& Coulson, 2005). If a gesture does not match speech or the preceding context, the brain is as surprised as when speech is inconsistent, as revealed by $N 400$ effects in electrophysiological measures of brain responses (EEG, ERP).

Various theories attempt to account for the relationship between speech and gesture, and to specify the role gestures play for speakers. One set of theories sees gestures as an auxiliary system to speech (cf. Kendon, 2004). These either consider gestures to facilitate lexical retrieval (e.g. Krauss, Chen, \& Gottesman, 2000), or the representation and packaging of content to be verbalized (e.g. Alibali, Kita, \& Young, 2000; Freedman, 1977). Another set of theories views gestures and speech as equal partners and considers gestures to be an integral part of an utterance. These theories either assume that gestures and speech share the same cognitive origin (e.g. Kita \& Özyürek, 2003; McNeill, 2005) or that a common communicative intention drives output in two modalities (De Ruiter, 2000; Kendon, 2004).

Existing theories also differ in their view on the nature and the location of the link between gesture and speech. The Lexical Retrieval Model (e.g. Krauss et al., 2000) proposes that gestures are linked to speech at the level of speech formulation (cf. Levelt, Roelofs, \& Meyer, 1999). Gestures only occur when a speaker experiences a ford-finding problem to help activate lexical entries. In this perspective gestures are an epiphenomenon. Interestingly, advocates of this view also argue against any communicative relevance of gestures for interlocutors (e.g. Krauss, Chen, \& Chawla, 1996; see Kendon, 1994 for an overview of the debate). Others have suggested that gestures and speech are linked at the conceptual level, arguing that speech and gesture must be planned together to allow for the detail and flexibility of the temporal and semantic co-ordination. For instance, the Growth Point Theory states that speech and gesture form a fully integrated system where the modalities interact throughout planning and speaking (McNeill, 2005; McNeill \& Duncan, 2000). A growth point is the newsworthy element of thought containing both imagistic and 
linguistic content. It serves as the starting point of an utterance. As the thought is expressed, gesture and speech convey the information for which they are best suited. Under this view, gestures transpose abstractions back into the concrete and help internalize the abstract via the concrete, and therefore play an important role for the embodiment of cognition. This line of thinking has been influential in studies of cross-linguistic conceptualization and for metaphor in gesture and speech (e.g. Cienki, 1998; Núñez \& Sweetser, 2006). A related view, the Interface Hypothesis, holds that gestures are shaped by linguistic thinking but also by visuo-spatial properties, labeled spatial thinking (Kita \& Özyürek, 2003). Crucially, the two modes of thinking interact and influence each other online. The Sketch Model, finally, also assumes that gestures are planned with speech at the conceptual level (De Ruiter, 2000). In contrast to other models, it states that the actual realization of a gesture is driven by the communicative intent of the speaker as much as by the linguistic and spatial properties of the message alone. This model is the only one to attempt to account for all gesture types and also for the fact that speakers do not always gesture.

In sum, although the details of the relationship between gestures, language, and speech are not yet fully understood and the theories differ in their views on the mechanics, the actual link remains undisputed.

\subsection{Cross-linguistic gestural repertoires}

Although gestures are subject to individual variation (cf. Alibali, 2005), there is also uniformity in gesturing within groups. Individuals appear to differ with respect to how many gestures they perform, whereas speakers within a speech community and culture are remarkably consistent in when and how they gesture when communicative content and situation are kept constant. There seem to be gestural repertoires whose characteristics are motivated both by culture and by language.

Cultural norms concern "appropriate" gesture usage, typically suggesting that the less you gesture, the better (Schmitt, 1991). Cultural conventions also affect gestural form, most clearly reflected in the sets of culture-specific gestures (emblems) sometimes set down in dictionaries (for inventories, see Morris, Collett, Marsh, \& O'Shaughnessy, 1979; Payrató, 1993). More spontaneous forms of gesturing are also subject to cultural conventions such as back-channel signals like nodding and headshaking (cf. Kendon, 2002; Maynard, 1990; McClave, 2000), pointing (e.g. Haviland, 1993; Sherzer, 1972; Wilkins, 2003), and use of gesture space (e.g. Müller, 1994).

Systematic differences between and uniformity within gestural repertoires also appear to be motivated by language. For instance, the organization of information structure in speech is reflected in gesture. A number 
of studies have shown that gestures tend to co-occur with elements in speech that represent new or focused information (e.g. Levy \& McNeill, 1992; McNeill, Levy, \& Cassell, 1993). Cross-linguistic differenees in how information is organized and implemented in discourse therefore lead to language-specific gesture patterns (e.g. McNeill \& Duncan, 2000). For instance, Dutch, Swedish, and French speakers treat actions as newsworthy, whereas Japanese speakers are more interested in locations and settings for actions. These different linguistic foci are instantiated in different structures in speech: transitive constructions centering on actions on the one hand, and existential constructions introducing entities and settings on the other. These different constructions in turn yield different gesture patterns, with Dutch, French, and Swedish speakers gesturing more about actions, aligning gestures with verbal elements, and Japanese speakers gesturing more about entities forming the setting, aligning gestures with nominal expressions (Gullberg, 2003; 2006a; Yoshioka, 2005; Yoshioka \& Kellerman, 2006).

Moreover, there is a growing body of work demonstrating that languagespecific lexicalization patterns are reflected in gesture as a result of the semantic and temporal co-ordination between speech and gesture (e.g. Duncan, 1994; Gullberg, submitted; Kita \& Özyürek, 2003; McNeill \& Duncan, 2000; Müller, 1994). Speakers must constantly make choices about what aspect of reality to talk about and how to talk about it. This selection is alternatively referred to in the literature as linguistic conceptualization, event construal, or perspective taking. Factors that guide the choices include communicative intent (Lakoff \& Johnson, 1980, p. 163), the underlying quaestio to be answered (Von Stutterheim \& Klein, 2002), and shared knowledge or common ground (e.g. Clark, 1996). It has also been suggested that speakers' choices are guided by the linguistic categories afforded by a language, specifically the categories that are habitually used to express events (e.g. Berman \& Slobin, 1994; Carroll \& Von Stutterheim, 2003; Slobin, 1996). This latter idea is known as the Thinking for Speaking Hypothesis (Slobin, 1996). ${ }^{1}$ Linguistic categories are assumed to guide attention to certain types of information that are then selected for expression. In this way language-specific thetorical styles or event perspectives arise (Slobin, 2004, Talmy, this volume).

Gestures seem to reflect such thetorical styles or perspectives both in terms of the information selected for expression and the way in which this information is subsequently encoded in speech. Gesture studies have often focused on expressions of voluntary motion, drawing on Talmy's typological distinction between satellite- and verb-framed languages (Talmy, 1985, see also Cadierno, Odlin, this volume). For instance, gestures accompanying motion expressions in English look different from the corresponding Turkish and Japanese gestures (Kita \& Özyürek, 2003; Ozyürek, Kita, Allen, Furman, \& Brown, 2005). 
(4) the ball [rolled down] the street

(5) [yuvarlan-arak] [cadde-den iniyor]

roll-Connective street-Ablative descend.present

"(s/he) descends on the street, as (s/he) rolls" (Kita \& Özyürek, 2003, p. 22)

English speakers express manner (roll) and direction of motion or path (down) in one spoken verbal clause, as in (4). They also tend to perform one single gesture that encodes both the manner and the path in one movement (a circling gesture moving in some direction, marked by square brackets in (4)). The tight syntactic packaging of manner and path components into one spoken verbal clause is reflected in a tight, conflated gesture. In contrast, Turkish speakers use two lexical verbs in two verbal clauses, as in (5): one verb expressing the manner (yuvarlan) and the other the downward motion (iniyor). Turkish speakers are also more likely to perform two accompanying gestures, one expressing the manner only and another path only. The looser syntactic connection between the manner and path components in speech is reflected in separate gestures. Kita and Özyürek (2003) have argued that the distinct gesture patterns hinge on the linguistic lexicalization patterns: a tight one-clause-one-gesture pattern vs. a looser two-clauses-two-gestures pattern. This claim is supported by the observation of within-language variation depending on what structures speakers actually use (Özyürek et al., 2005). When English speakers use a two-clause construction, they too are more likely to produce two gestures.

Verb semantics also influence gestures even in the absence of overt syntactic differences. When talking about caused motion or placement speakers of Dutch and French gesture differently (Gullberg, submitted). Both languages use transitive constructions followed by locational phrases of the type "she put the cup on the table." But French typically uses a general placement verb, mettre, "put," whereas Dutch uses a set of fine-grained semi-obligatory posture verbs, zetten, leggen, "set," "lay." Critically, the choice of verb hinges on properties of the object being placed and its final disposition with respect to the goal ground. The importance of the object for verb choice in Dutch is reflected in gestural handshapes that incorporate the object. French speakers instead focus only on the direction of the placement movement, mirrored in gestures that only express path.

Other factors also contribute to forming gestural repertoires. Situation and context, level of formality and familiarity with the interlocutor, education, mood, what is being talked about, genre, didactic intent, etc., all modulate gestural behavior. This said, language remains a fundamental influence. Speakers of different languages have different gestural repertoires partly for linguistic reasons. Speakers do not necessarily do what they see but rather what they say. Gestures reflect linguistic choices both 
at the level of information structure and at the level of lexical choices as instantiated in both syntax and semantics.

\section{Gestures in Second Language Acquisition}

\subsection{Gestures and the development of a particular L2}

The linguistic influences on gestural repertoires open up new methodological possibilities for examining effects of cross-linguistic influence or transfer on the route and the speed of acquisition of a particular target language given a certain first language (cf. Odlin, 2005, this volume). Because gestures reflect linguistic choices, they can be useful for examining language-specific aspects of linguistic conceptualizations. A crosslinguistic difference in event construal can be evident in gesture, either in terms of where gestures fall (what is newsworthy) or in terms of how gestures look (what meaning elements are taken into account). Moreover, meaning elements relevant to the event construal that are not readily expressible in speech may nevertheless be visible in gesture as additional spatial information.

Shifting perspectives on events in an L2 is likely to be difficult for several reasons. Many cross-linguistic differences in this domain are more a matter of preferential patterns than of grammaticality (cf. Carroll, Murcia-Serra, Watorek, \& Bendiscoli, 2000). Although it is possible to say in English that "the ball descended the street while rolling," it is not the typical way of doing it. Kellerman's "transfer to nowhere" principle outlines the challenge in discovering differences not clearly marked as ungrammatical and difficulties in re-directing attention to new information elements. "[L]earners may not look for the perspectives peculiar to [the L2] language; instead, they may seek the linguistic tools which will permit them to maintain their $\mathrm{L} 1$ perspective. Such cases represent transfer to nowhere, an unconscious assumption that the way we talk or write about experience is not something that is subject to between-language variation" (Kellerman, 1995, p. 141, orig. emphasis). A substantial body of literature, conveniently summarized in Odlin (2005), documents these difficulties. It is equally challenging for the analyst to uncover the details of the perspective a learner actually operates with at a given point in time. A few studies investigate learners' gestures to uncover how the L1 and the L2 interact at the level of semantic-conceptual representations and their interface with information structure. The logic in these studies is the following. Under the theoretical view that gestures reflect linguistic conceptualization, two languages with different event construals should display different gesture patterns. If learners have acquired the L2 conceptualization, then their gestures should look L2-like. Any shift in learners' gestures reflects a shift in underlying representation. 
One line of research focuses on the timing of gestures to examine what aspects of an event speakers regard as most newsworthy. In the domain of motion, studies have examined with what speech elements speakers of Spanish, English, and Dutch align their gestures. Native speakers of Spanish overwhelmingly coordinate their path gestures with path verbs like salir, "go out," whereas English speakers show a more varied pattern, aligning their path gestures with path particles like "down," with particles and verbs together, with verbs alone, and with expressions of ground (Kellerman \& Van Hoof, 2003; McNeill \& Duncan, 2000; Negueruela, Lantolf, Rehn Jordan, \& Gelabert, 2004). Stam (2006) investigated Spanish learners of English at different proficiency levels. Many learners continued to align their path gestures in L2 with verbs in the L1 fashion, suggesting that they still considered the path (and the verb) to be the most newsworthy element of the motion event. Although some learners did align their path gestures with verbs and particles in English stylesuggesting a beginning shift of focus-these gestures tended to accompany general motion verbs like "go" more often than in native English discourse, where verbs typically express manner information. Similarly, Kellerman and Van Hoof (2003) found that Spanish learners of English placed their path gestures on verbs in L2 and interpreted this as a case of L1 transfer. However, Dutch learners of English unexpectedly also placed their gestures mainly on verbs, although Talmy's typology suggests that their L1 Dutch should favor an English-like focus on (verbs and) particles. The authors cautiously refrain from explaining this finding, but the gesture data raise the possibility that learners consider path as the most newsworthy element of motion regardless of their L1. If so, this would suggest a possible language-neutral stage of event construal in acquisition.

Another strand of research focuses more on the shape, form, and content of gestutes, examining what information is packaged together and how. In a set of beginning, intermediate, and advanced Turkish learners of English, only the advanced group was capable of expressing manner and path in one clause in spoken L2 English ("roll down") (Özyürek, $2002 \mathrm{~b}$ ). Interestingly, this group nevertheless produced Turkish-like gestures expressing only manner or only path at least half of the time, tather than both manner and path in one gesture. Although L2 speech was reasonably target-like, suggesting a perspective shift, Özyürek argues that these learners still conceptualized the motion events in a Turkish manner, focusing either on manner or path components separately. Similar evidence for lingering L1 patterns of event construal is found in the expression of ground elements. Yoshioka and Kellerman (2006) examined Dutch learners of Japanese, i.e. leatners moving from a satellite-framed $L 1$ to a verbframed L2. As already seen, native Dutch speakers introduce grounds with mention of the action and gesture mainly about the action. Native Japanese speakers instead introduce grounds in chains of existential clauses 
with separate gestures for each ground mentioned. The Dutch learners of L2 Japanese continued to introduce ground together with action in both L2 speech and L2 gesture. These two studies indicate that L1 influences are sometimes visible in both modalities simultaneously, and sometimes only in one.

Other research focuses on the distribution of meaning components across speech and gesture in L2. Two studies have found that Spanish learners of English tend not to express manner in L2 speech but only in gesture (Negueruela et al., 2004; Wieselman Schulman; 2004). Negueruela et al. also found the same pattern for English learners of Spanish. The absence of manner in spoken L2 English is assumed to be due to crosslinguistic influence. Because manner of motion is not a core part of the learners' L1 Spanish event construal, they are assumed to have difficulties encoding it in L2 English speech. The absence of manner in spoken L2 Spanish is of course accurate since manner of motion is not compulsory in Spanish. But why should both groups express manner in L2 gesture? Interestingly, the accounts differ for the two groups. McNeill and Duncan (2000) have suggested that gestures modulate the communicative relevance of manner in native English speech. The presence of manner gestures foregrounds it and their absence backgrounds it. In native Spanish, in contrast, manner gestures regularly occur even when manner is absent from speech in so called "manner fogs." Here it is argued that, because Spanish has no simple (verbal) encoding option for manner in speech, gestures regularly convey the information. The consequence for the L2 data is that Spanish learners of English may continue to rely on gesture for expressing manner as part of an L1-based procedure, i.e. as a form of transfer. For English learners of Spanish, in contrast, manner gestures may instead be a compensatory strategy. English speakers are used to encoding manner in L1 speech. Because Spanish is poor in manner verbs, they cannot find an outlet in L2 speech, and therefore instead rely on gesture.

These findings highlight the common assumption that abandoning an L1 category with no L2 equivalent is easief than creating an L2 category with no L1 equivalent. That is, splitting categories is difficult, but merging two existing categories is assumed to involve mere re-labeling. However, if linguistic categories reflect particular event construals; all transitions should involve adjustments of representations regardless of whether they involve splitting or merging. Gesture data can ptovide some information on the elusive processes underlying merging. Dutch learners of French accurately use the French placement verb, mettre, "put," in L2 as they move from their two finer-grained L1 categories, zetten, "set," and leggen, "lay" (Gullberg, fotthcoming). However, to "mean" the same thing by mettre as native speakers of French, they must shift interest away from objects and towards a path-only-oriented perspective. Their gestures 
reveal both French-like, Dutch-like, and mixed patterns suggesting that different learners operate with different representations for their L2 surface forms. Moreover, the gesture evidence indicates that te-organization of perspective or representations in $\mathrm{L} 2$ acquisition is a gradual process with intermediate stages where both L1 and L2 perspectives come into play. Nevertheless, full adjustment is not beyond the tealm of the possible since some learners do gesture in a French-like fashion.

Cross-linguistic influences may also operate from L2 to L1 in that an emerging L2 may influence an established L1 ( $\mathrm{ff}$. Cook, 2003; Pavlenko \& Jarvis, 2002). This is not necessarily a matter of language loss or attrition, nor indeed an effect of advanced bilingualism, but rather the normal result of processing more than one language regardless of proficiency. Such bi-directional influences are amply documented in the literature on lexical processing (e.g. Costa, 2005; Dijkstra, 2005). There is also preliminary evidence for such effects in lexicalization. Native Japanese speakers with intermediate knowledge of English speak and gesture differently about motion events in their $\mathrm{L} 1$ than monolingual Japanese speakers (Brown, 2007). They introduce more path elements in L1 Japanese speech, notably expressions of source and goal. Interestingly, in gesture they also adopt more observer-viewpoint petspectives on events than monolingual Japanese speakers who prefer a charactet-viewpoint perspective (cf. McNeill, 1992). This means that monolingual Japanese speakers perform enacting gestures as if they themselves were the protagonists in a story. Japanese speakers who know some English instead typically represent entities or events in gestures as seen from a distance and not as if they themselves were performing them. Although the speech and gestutes are perfectly grammatical, the gesture data in particular suggest that Japanese speakets with knowledge of English construe motion events differently from monolinguals. Observations like these have theoretical and methodological implications, btinging SLA and bilingualism studies closer.

To summarize, gesture analyses of learner production allow additional information to be gleaned on how $L 2$ learners adjust representations and perspectives on events as they go from a certain L1 to a certain L2. Both the timing and form of gestures provide information about gradual changes and intermediate shifts in L2 linguistic conceptualization that may go undetected especially where speech is formally, if not distributionally, target-like. The combined analysis of gesture and speech reveal more about the difficulties learners have in shifting linguistic conceptualization than speech alone. The findings suggest two typical L2 patterns, one where gestures and speech indicate a unified (wholly L1-like) event construal, and one disjoint construal where the modalities show discrepancies. Note, however, that most gesture studies to date tend to assume that any L.2 pattern that does not conform to the target is solely due to 
properties of the L1. This is both theoretically and methodologically illfounded. Transfer can only be established when learners with different L1s learning the same target L2 are examined. Only then can alternative explanations such as general learner effects be ruled out (cf. Jarvis, 2000).

\subsection{Gestures and $\mathrm{L} 2$ development in general}

SLA research is not only restricted to comparisons of interlanguage against L1 and L2 norms but also focuses upon interlanguage as a systematic and regular variety in its own right, a learner-variety (cf. Bley-Vroman, 1990; Klein \& Petdue, 1997). Gestures contribute to this line of study as well. Systematically parallel changes in gesture and speech at a given point in development allow us to investigate interactions between communicative and more process-related constraints on learner varieties.

\subsubsection{L2 gestures as indicators of expressive difficulties}

It has frequently been observed that $\mathrm{L} 2$ learners produce more gestures when speaking the L2 than when speaking their L1 (e.g. Gullberg, 1998; Sherman \& Nicoladis, 2004; for exceptions, see e.g. Wieselman Schulman, 2004). One of the presumed reasons for this is proficiency, or more precisely, the notion that gestures reflect increased difficulties and that learners' gestures compensate for speech problems. The view of gestures as a compensation device in production and comprehension is popular in studies of aphasia (cf. Rose, 2006) and specific language impairment (Fex \& Månsson, 1998). Although it is clear that not all L2 gestures are motivated by compensatory needs, it is equally clear that L2 learners can and do use gestures as part of their cognitively and interactionally motivated communication strategies (CSs) to overcome various expressive problems (Gullberg, 1998). L2 learners use gestures strategically for three main purposes: to compensate for lexical shortcomings, to alleviate grammatical difficulties, and to manage fluency-related problems.

First, learners use gestures to solve lexical dilemmas. Contrary to popular expectation, these gestures do not replace speech but typically occur with speech, often a spoken strategy such as an approximation or circumlocution. These are also joint solutions since learners use gestures to elicit lexical help from the interlocutor. Such gestural solutions work equally well for concrete and abstract items in that abstract concepts are given concrete properties in representational gestures (e.g. Gullberg, 1998; McCafferty, 1998).

Second, learners also use gestures to overcome grammatical difficulties such as those related to tense and temporality. By mapping time onto space metaphorically, learners can gesturally refer to spatial time axes to establish temporal relationships quite precisely even in the absence of 
adequate temporal morphology in speech (Gullberg, 1999). Again, the use of gestures is closely linked to the use of temporal lexical items that help clarify the relationship between locations on the time axes.

Finally, the troublesome interaction that results from accumulated difficulties and non-fluency yields the most frequent type of gesture in L2 production: metapragmatic gestures (Gullberg, 1998). In speakers of Western-European languages these gestures frequently involve circling movements of the wrist or wriggling fingers. They often occur during communicative breakdowns and they flag the fact of an ongoing word search, but not its content. En route, they also serve efficiently to hold the learner's turn and to elicit clarification or confirmation (cf. Duncan, 1972; Schegloff, 1984; Streeck \& Hartege, 1992). These gestures are interactional glue that help sustain and facilitate positive interaction between the non-native and native participants (Bavelas et al., 1992; McCafferty, 2002).

To simply equate higher gesture rate with more difficulty is clearly not sufficient. Different types of difficulties affect different types of gestures. Much more information can be gained if these differences in types and functions are considered. For instance, a shift in reliance on a particular gesture type can shed light on shifts in different interlanguage domains. Taranger and Coupier (1984) showed how, with growing proficiency, Moroccan learners of French changed from using mainly representational gestures complementing the content of speech towards more emphatic or rhythmic gestures related to discourse. Similar development is reported for Japanese learners of French residing in France (Kida, 2005). This suggests a transition from essentially lexical difficulties and lexically based production to more grammatical problems related to discourse. More careful charting of what gestures are produced by learners with particular proficiency profiles has potential pedagogical and diagnostic applications.

\subsubsection{Constraints on learner varieties}

A different approach takes spoken learner phenomena as the starting point for examining gestural correlates with a view to improving our understanding of learner varieties. For example, many early L2 learners of different $L 1 s$ and $L 2 s$ have similar difficulties maintaining reference in discourse. They often use full lexical noun phrases (NPs) instead of pronouns to refer back to an entity just mentioned, leading to clause chains like "the woman ... the woman ... the woman" instead of "the woman ... she ... ø." Such chains form over-explicit, ambiguous, and noncohesive speech since new and given information cannot be distinguished (e.g. Givón, 1984; Hendriks, 2003). The over-explicitness in speech is mirrored in the gestures of Swedish, French, and Dutch learners at low levels of proficiency (Gullberg, 2003; 2006a; Yoshioka, 2005; Yoshioka \& 
Kellerman, 2006). Learners anchor entities talked about in space with gesture at their first mention, and then anaphorically refer back to that same location at the immediate next mention if labeled by a lexical NP in speech. This gestural behavior changes with grammatical development in speech (Gullberg, 2003). Once pronouns are used for maintained reference, the number of anaphoric gestures drops significantly. Importantly, the properties of $\mathrm{L} 2$ speech do not depend on the presence of disambiguating anaphoric gestures. Learners' speech remains over-explicit whether their interlocutors can see their disambiguating gestures or not (Gullberg, 2006a). Further, the gestures do no disappear when interlocutors cannot see them, indicating that their presence is not motivated by concerns of ambiguity. Interestingly, however, the gestures are less spatially distinct when they cannot be seen. This suggests that if visible, learners do tailor their gestures for the interlocutor such that they can be exploited for disambiguation. But, overall, the core properties of both speech and gesture seem to depend on development and not to be motivated by communicative concerns, even if communication influences the actual articulation of gestures.

Gestures can thus enrich the analyses of general properties of L2 development illuminating the interplay between cognitive constraints and communicative pressures. Both factors shape learner production when situated in interaction and the combined analysis of speech and gesture contributes to more fine-grained accounts of how their relative weight plays out.

\section{Gestures and (language) learning}

\subsection{Gestures as input-does seeing gestures help?}

Interlocutors are known to attend to and make use of gestural information, for instance to improve comprehension in noise (Rogers, 1978). A natural assumption is therefore that gestures that convey speech-related meaning should improve language learners' comprehension and possibly also learning (cf. Harris, 2003; Kellerman, 1992). Instructors or competent speakers seem to sense this. Almost all forms of "instructional communication" or didactic talk have gestural correlates characterized by an increased use of representational and rhythmic gestures (Allen, 2000; Gullberg, 1998). This has been observed in foreigner talk (Adams, 1998), teacher talk (e.g. Hauge, 2000; Henzl, 1979; Lazaraton, 2004), caregiver talk (e.g. Garnica, 1978; Iverson, Capirci, Longobardi, \& Caselli, 1999), and academic lectures (e.g. Corts \& Pollio, 1999). There is some support for the notion that gestures improve comprehension in L2 contexts. Sueyoshi and Hardison (2005) found that low-proficiency learners did understand a lecture on ceramics in L2 English better when gestures were 
present. They also benefited more from gestures than more proficient learners. Tellier (2006) shows that French five-year-olds understand the main events of a story told in English, a completely unknown language, if accompanied by iconic gestures. However, the broad claim that gestures improve comprehension may be too general. Musumeci (1989) tested tense assignment in L2 English by beginner EFL learners with different Lis. Three cues to tense were available: temporal adverbials, verb morphology, and gestures indicating temporal reference (past behind, present in front of, and future away from speaker). All learners relied on temporal adverbials, with advanced learners also exploiting morphology. In no group did gestures have a significant effect. The facilitative effect of gestures may depend on the nature of the linguistic units illustrated and be more evident for lexical than grammatical material. Moreover, different gesture types clearly have different effects. While speech-associated gestures may help, culture-specific, conventionalized gestures will not confer comprehension benefits unless they have been explained, as suggested by studies showing that leatners do not understand foreign emblems weil (e.g. Mohan \& Helmer, 1988; Wolfgang \& Wolofsky, 1991) without instruction (Jungheim, 1991).

Gesture input also seems to promote actual learning. Children learning about mathematical equivalence (Singer \& Goldin-Meadow, 2005) and the concept of symmetry (Valenzeno, Alibali, \& Klatzky, 2002) all benefit from their teachers' gestures, especially when these convey more information than speech. In the domain of language, English three-year-olds learn new adjectives such as "spongy" better if they are taught the adjective while shown a descriptive squeezing gesture, than if the adjective is introduced with only a pointing gesture (O'Neill, Topolovec, \& Stern-Cavalcante, 2002). For SLA, the available evidence is scarce but indicative of similar benefits. Allen (1995) showed that learners who received explanations of French vocabulary with emblematic gestures learned more and forgot significantly fewer words than learners who bad not received gesture input with the explanations.

Accounts for why gestural input is helpful typically suggest that gestures capture attention, provide semantic redundancy, and genetally engage more senses by grounding speech in the concrete, physical experience (cf. Hostetter \& Alibali, 2004). A possible neurocognitive account pertains to mirror neurons, suggesting that the same areas in motor cortex are activated when observing others' actions and (presumably) gestures as when performing them yourself (e.g. Rizzolatti \& Craighero, 2004). Similarly, recent work on "embodied cognition" (eg. Glenberg \& Kaschak, 2002) suggests that comprehension is grounded in action. Words like doorknob activate knowledge of the hand shape in clenching (Klatzky, Pellegrino, McCloskey, \& Doherty, 1989). Seeing gestures might therefore improve comptehension and learning because sensori-motor experience 
is evoked. These various explanations need not be mutually exclusive. However, some options could be explored experimentally for the full pedagogical implications for SLA to become clearer. It is an empirical challenge to determine which gestures may help with what both inside and outside the language classroom.

\subsection{Gestures as output-does producing gestures help?}

It has recently been suggested that gestures not only help listeners but also speakers themselves. For instance, children who gesture while learning about math perform better than children who do not (Alibali \& DiRusso, 1999). Adult learners also benefit from gesturing as they reason about novel concepts in science (e.g. Crowder, 1996; Roth, 2003), and medicine (Alac, 2005; Koschmann \& LeBaron, 2002). Very few studies actually test learning effects of gesturing in SLA. The majority of studies instead rely on indirect measures. Scholars working within a socio-cultural theory perspective argue that producing gestures helps language learners internalize new knowledge related to various domains in the $L 2$ through enactment or processes of embodiment (e.g. Negueruela et al., 2004). For example, McCafferty $(2004 ; 2006)$ proposes that a learner's thythmic gestures may support the acquisition of $\mathrm{L} 2$ prosodic structure. He argues that beats may help learners parse and structure the rhythmic pulse of an L2 as they attempt to master syllable structure. This highly interesting suggestion could and should be empirically tested. The input and output perspectives have also been combined to examine measurable effects on comprehension and lexical learning in the teaching of English as a foreign language to French children (Tellier, 2006). Children who receive gestural input with vocabulary explanations retain significantly more items than those who do not. Importantly, children who also reproduce the gestures themselves perform even better than children who do not even if they have had gestural input.

Why should producing gestures help learning? One account is essentially communicative. In many cases, childyen and adults talking about new and poorly mastered notions convey additional or redundant information in gestures compared to speech (sometimes called "mismatches," cf. Alibali \& Goldin-Meadow, 1993; Goldin-Meadow, 2003). In developmental psychology this discrepancy between speech and gesture has been interpreted as an indication of transitional knowledge states. Interestingly, speakers displaying such discrepancies seem to be ready to learn and benefit most from instruction (Church \& Goldin-Meadow, 1986; Goldin-Meadow, 2003). Adults and teachers are sensitive to these discrepancies and tailor their own speech-gesture production to the learners' levels (Goldin-Meadow, 2003). In this sense, learners help themselves by gesturing because their gestures influence their interlocutors, prompting 
these to create optimal input for the learners (cf. the Comprehensible Input Hypothesis, Krashen, 1994). In addition, learners' gestures generate positive attitudes between them and their addressees (McCafferty, 2002), which may increase the opportunities for using the L2 further and promote continued output (cf. the Output Hypothesis, Swain, 2000). This is also assumed to promote language learning. The positive interactional effects of learners' gestures carry over to assessment. Learners who are seen to gesture are often more positively evaluated on proficiency than those who are not (Gullberg, 1998; Jenkins \& Parra, 2003; Jungheim, 2001).

Alternative cognitive explanations tend to focus on general cognitive gains of gesturing without making specific claims about learning. For instance, cognitive psychology has demonstrated an effect of enaction on memory. Enacted action is better recalled than action phrases without enactment (Engelkamp \& Cohen, 1991) and self-enactment improves recall more than seeing someone else enacting (Frick-Horbury, 2002). More generally, the gestural Information Packaging Hypothesis proposes that gestures help speakers plan what to say. By performing a gesture, speakers can explore aspects of their communicative intentions and more easily select, package, and linearize spatial information into verbalizable units (cf. Alibali et al, 2000). Such facilitation in conceptual and linguistic planning may help learning. A more process-oriented proposal is that gesturing reduces cognitive load on working memory (Goldin-Meadow, Nusbaum, Kelly, \& Wagner, 2001). In a task where speakers have to memorize word lists while they explain a math problem, those speakers who gesture during the math explanation subsequently recall more words than those who do not. The argument is that by gesturing speakers unload cognition onto an external representation, thereby liberating processing resources which can be re-assigned to memorization, planning, or other working-memory intense operations. This account is particularly tempting for SLA since it could explain why learners produce so many gestures when they are barely fluent, even when their interlocutors cannot see their gestures. It is possible that L2 learners' gestures reflect their attempts to reduce the processing load of keeping words, grammar, and the relationships between entities in mind at the same time as planning what to say next. In this sense, gestures may help learners to keep talking. Again, in and of itself this is not a direct explanation for actual learning but fits in well with the effects to be gained from producing sustained output and from influencing your interlocutors positively. As before, the communicative and cognitive explanations need not be mutually exclusive. 


\section{The gesture challenges}

The analysis of $\mathrm{L} 2$ gestures raises some important theoretical questions regarding the relationship between surface forms, representations and conceptualization, as well as about the status of gestures as mediating between them. I2 gesture data in fact put both gesture and L2 theories under pressure. In native contexts gestures are assumed to tap semantic or conceptual representations (and implicit knowledge) more directly than speech. They are also influenced by surface form such as the actual syntactic constructions chosen to encode semantic components (e.g. Özyürek et al., 2005). Generally, the link to conceptualization is believed to be stronger than to speech by virtue of the fact that gestures can be "ahead" of speech and express knowledge states and information not yet available for linguistic or explicit expression (cf. Goldin-Meadow, 2003). This predicts that representations should change first, followed by gestures and then speech. L2 data pose problems for all of the above. Learners' gestures display a dissociation between surface form and gesture and therefore potentially also between surface form and representations. Learners often continue to align their gestures with spoken elements that reflect L1- rather than L2-typical foci. They can also express meaning in gesture that reflects semantic or conceptual material from the L1 even as they are expressing other semantic elements in the spoken L2. They gesture one thing, and say another. Strikingly, in the L2 studies reviewed speech is overall more likely to be target-like than gestures; $L 2$ speech appears to change towards the target before gestures do. Very few attempts have been made to account for this L2-specific form of speech-gesture discrepancy. It prompts questions, however, regarding what kind of representations actually underpin L2 surface forms. When I2 surface form and gesture both look L1-like, the relationship is clear. However, when L2 speech looks target-like and gesture does not, it is unclear on what representations the spoken L2 forms are based. How can Turkish learners use accurate constructions like "roll down" in speech if they underlyingly still focus on path or on manner separately? More generally, the looser link between spoken and gestural form begs the question of how great the overlap in meaning between the modalities must be in order to be considered a match in representation or conceptualization. Answers to these questions will contribute in important ways to theories of gesture as well as of SLA.

A view of Second Language Acquisition that takes gestures into account also ups the stakes for notions like native-likeness and ultimate attainment (Birdsong, 2004; 2005). Gestures expand the scope of inquiry by providing more dimensions along which learners' utterances and discourse can vary. With this extra information ever more subtle details about the speech production process can be explored and gauged against 
native speakers. Equally, evidence that gesture patterns typical of the $\mathrm{L} 2$ find their way into the L1 also challenges the notion of a monolithic, monolingual native standard (cf. Davies, 2003). Moreover, gestures push the boundaries further if viewed as a modality to which judgments of target likeness apply per se. Under the assumption that language consists of speech. and gestures as a "composite signal" (Clark, 1996), learning a new language also entails learning a new gesture repertoire (e.g: Antes, 1996; Von Raffler-Engel, 1980). The acquisition of L2 gesture can be studied in a product-oriented way just like speech, to determine "crossgestural" influences between $\mathrm{L} 1$ and $\mathrm{L} 2$, for example. The $\mathrm{L} 1$ use of gesture space, small or large, may carry over to L2 production (cf. Kida, 2005). Culture-specific emblems may cause similar trouble in L2 comprehension and production as idiomatic expressions (e.g. Jungheim, 2006). Moreover, new ways of back-channeling or pointing are probably hard to acquire given their semi-conventional but highly automatized nature. The extent to which L2 learners actually acquire any aspect of L2 gestures is a sorely understudied area both in comprehension and production for conventional and speech-associated gestures alike (cf. Gullberg, 2006b).

Clearly, the acquisition of gestural repertoires represents an enormous challenge to language learners and educators. Very little is known about gestural repertoires - forms, usage patterns - beyond what is described in this chapter. What might be learnable and indeed teachable (and therefore assessable) is entirely unknown regardless of the definition of implicit and explicit knowledge and learning. Conversely, it is not known whether non-native-like gesturing, "foreign gesture," is as disruptive to interlocutors as foreign accent. While anecdotally plausible, it remains an open empirical question until a perceptual foreign gesture study is undertaken. Much work lies ahead to expand our knowledge of culture- and languagespecific gestural repertoires, form-function relationships in more linguistic domains, contexts, and settings, and the range of variation in native tepertoires. Methodological rigor and teplicability is fundamental to these endeavors and precise procedures and descriptions are needed that carefully consider the multifunctional nature of gestures. Since gestures can be motivated by many different underlying mechanisms and processes-especially in L2 production where lexical, syntactic, conceptual, and interactive difficulties converge-rigorous criteria must be applied to ensure that relevant gesture types are considered.

\section{Conclusions}

This chapter set out to demonstrate why gestures are relevant to SLA. The grand answer is that gestures enable us to study the interactions between communicative and cognitive, process-related constraints on L2 
development in novel detail. Gestures are at once interactive, spatio-visual phenomena and also closely tied to sophisticated speaker-internal, linguistic processes. They therefore allow a richer perspective to be taken on the processes of language acquisition in which the learner's individual cognition is situated in a social, interactive context. Gestures can be studied in their own right as external representations of meaning and communicative intentions. They also offer new possibilities as a tool to examine old L2 issues in novel ways. For example, differences between tutored and untutored learners and early simultaneous bilinguals may be explored in more detail, considering acquisition both as a product and as a process. Gestures open new ways to examine the SLA of meaning to complement and expand the current predominant focus on form, allowing issues of broad conceptualization, categorization, and syntactic form to be fruitfully brought together. Because the distribution of meaning components in gesture and speech is not necessarily one-to-one, gesture may also promote a focus on broader units of analysis, like utterance or discourse, which enable a fuller picture of the learner's language activity to be gleaned. The ultimate challenge is to integrate gestures, as communicatively and cognitively relevant entities, into the wider field of SLA such that they can feed into and inform cognitive, linguistic, and cognitive linguistic theories of L2 learning and L2 use.

\section{Notes}

I am indebted to David Birdsong and Nick C. Ellis for helpful comments on an earlier draft. All remaining nonsense is my own.

1 Notice that the Thinking for Speaking Hypothesis (TFS) differs in scope from traditional linguistic relativity (Gumperz \& Levinson, 1996; Sapir, 1951). The TFS hypothesis specifically targets linguistic conceptualization whereas linguistic relativity proper assumes that linguistic caregories affect general cognition outside language. Gestures have been used to support arguments of linguistic relativity, too, for instance in the domain of spatial frames of reference (Haviland, 1996; Levinson, 2003).

\section{Bibliography}

Adams, T. W. (1998). Gesture in foreigner talk. Unpublished PhD diss., University of Pennsylvania.

Alac, M. (2005). From trash to treasure: Learning about brain images through multimodality. Semiotica, 156(1-4), 177-202.

Alibali, M. W. (2005). Gesture in spatial cognition: Expressing, communicating, and thinking about spatial information. Spatial Cognition \& Computation, 5(4), 307-331.

Alibali, M. W., \& DiRusso, A. A. (1999). The function of gestures in learning to count: More than keeping track. Cognitive Development, 14(1), 37-56. 
Alibali, M. W., \& Goldin-Meadow, S. (1993). Gesture-speech mismatch and mechanisms of learning: What the hands reveal about a child's state of mind. Cognitive Psychology, 25, 468-523.

Altbali, M. W., Heath, D. C., \& Myers, H. J. (2001). Effects of visibility between speaker and listener on gesture production: Some gestures are meant to be seen. Journal of Memory and Language, 44(2), 169-188.

Alibali, M. W., Kita, S., \& Young, A. J. (2000). Gesture and the process of speech production: We think, therefore we gesture. Language and Cognitive Processes, $15(6), 593-613$.

Allen, L. Q (1995). The effect of emblematic gestures on the development and access of mental representations of French expressions. Modern Language Journal, 79(4), 521-529.

Allen, L. Q. (2000). Nonverbal accommodations in foreign language teacher talk. Applied Language Learning, 11, 155-176.

Antes, T. A. (1996). Kinesics: The value of gesture in language and in the language classroom. Foreign Language Annals, 29(3), 439-448.

Bavelas, J. B., Chovil, N., Lawrie, D. A., \& Wade, A. (1992). Interactive gestures. Discourse Processes, 15(4), 469-489.

Beattie, G., \& Shovelton, H. (2002). An experimental investigation of some properties of individual iconic gestures that mediate their communicative power. British Journal of Psychology, 93(2), 179-192.

Berman, R., \& Slobin, D. I. (1994). Filtering and packaging in nartative. In R. Berman \& D. I. Slobin (Eds.), Relating events in narrative: A cross-linguistic developmental study (pp. 515-554). Hillsdale, NJ: Erlbaum.

Bitdsong, D. (2004). Second language acquisition and ultimate attainment. In A. Davies \& C. Elder (Eds.), Handbook of Applied linguistics (pp. 82-105). London: Blackwell.

Birdsong, D. (2005). Nativelikeness and non-nativelikeness in L2A research. International Review of Applied Linguistics, 43(4), 319--328.

Bley-Vroman, R. (1990). The logical problem of foreign language learning. Linguistic Analysis, 20, 3-49.

Brown, A. (2007). Crossinguistic influence in first and second languages: Convergence in speech and gesture. Unpublished PhD diss., Boston University, Boston.

Carroll, M., Murcia-Serra, J., Watorek, M., \& Bendiscoli, A. (2000). The relevance of information organization to second language acquisition studies: The descriptive discourse of advanced adult learners of German. Studies in Second Language Acquisition, 22(3), 441-466.

Carroll, M., \& Von Stutterheim, C. (2003). Typology and information organisation: perspective taking and language-specific effects in the construal of events. In A. G. Ramat (Ed.), Typology and second language acquisition (pp. 365-402). Berlin: Mouton.

Cassell, J., McNeill, D., \& McCullough, K.-E. (1999). Speech-yesture mismatches: Evidence for one underlying representation of linguistic and nonlinguistic information. Pragmatics 8 Cognition, 7(1), 1-33.

Church, R. B., \& Goldin-Meadow, S. (1986). The mismatch between gesture and speech as an index of transitional knowledge. Cognition, 23(1), 43-71.

Cienki, A. (1998). Metaphoric gestures and some of their relations to verbal metaphoric expressions. In J.-P. Koenig (Ed.), Discoutrse and cognition. Bridging 
the gap (pp. 189-204). Stanford, CA: Center for the Study of Language and Information Publications.

Clark, H. H. (1996). Using language. Cambridge: Cambridge University Press.

Cook, V. (2003). Introduction: The changing $\mathrm{L} 1$ in the L2 user's mind. In V. Cook (Ed.), Effects of the second language on the first (pp. 1-18). Clevedon: Multilingual Matters.

Corts, D. P., \& Pollio, H., R. (1999). Spontaneous production of figurative language and gesture in college lectures. Metaphor $\mathscr{E}$ Symbol, 14(2), 81-100.

Costa, A. (2005). Lexical access in bilingual production. In J. F. Kroll \& A. M. De Groot (Eds.), Handbook of bilingualism. Psycholinguistic approaches (pp. 308-325). Oxford: Oxford University Press.

Crowder, E. M. (1996). Gestures at work in sense-making science talk. Journal of the Learning Sciences, 5(3), 173-208.

Davies, A. (2003). The native speaker: myth and reality. Clevedon: Multilingual Matters.

De Ruiter, J.P. (1998). Gesture and speech production. Unpublished PhD diss., University of Nijmegen.

De Ruiter, J.-P. (2000). The production of gesture and speech. In D. McNeill (Ed.), Language and gesture: Window into thought and action (pp. 284-311). Cambridge: Cambridge University Press.

Dijkstra, T. (2005). Bilingual visual word recognition and lexical access. In J. F. Kroll \& A. M. De Groot (Eds.), Handbook of bilingualism. Psycholinguistic approaches (pp. 179-201). Oxford: Oxford University Press.

Duncan, S. (1994). Grammatical form and "thinking-for-speaking" in Mandarin Chinese and English: An analysis based on speech-accompanying gesture. Unpublished $\mathrm{PhD}$ diss., University of Chicago, Chicago.

Duncan, S. J. (1972). Some signals and rules for taking speaking turns in conversation. Journal of Personality and Social Psychology, 23(2), 283-292.

Efron, D. (1941/1972). Gestures, race and culture (First edition 1941 as Gestures and environment. New York: King's Crown Press. ed.). The Hague: Mouton.

Ekman, P., \& Friesen, W. V. (1969). The repertoire of nonverbal behavior: Categories, origins, usage, and coding. Semiotica, 1(1), 49-98.

Engelkamp, J., \& Cohen, R. L. (1991). Current issues in memory of action events. Psychological Research, 53, 175-182.

Fex, B., \& Månsson, A.C. (1998). The use of gestures as a compensatory strategy in adults with acquired aphasia compared to/children with specific language impairment (SLD). Journal of Neurolinguistics, $11(1-2), 191-206$.

Freedman, N. (1977). Hands, wotds, and mind: On the structuralization of body movements during discourse and the capacity for verbal representation. In N. Freedman \& S. Grand (Eds.), Communicative structures and psychic structures: A psychoanalytic approach (pp. 109-132). New York: Plenum Press.

Frick-Horbury, D. (2002). The use of hand gestures as self-generated cues for recall of verbally associated targets. American Journal of Psychology, 115(1), $1-20$.

Garnica, O. K. (1978). Non-verbal concomitants of language input to children. In N. Waterson \& C. Snow (Eds.), The development of communication (pp. 139-147). New York: Wiley. 
Givón, T. (1984). Universals of discourse structure and second language acquisition. In W. E. Rutherford (Ed.), Language universals and second language acquisition (pp. 109-136). Amsterdam: John Benjamins.

Glenberg, A. M., \& Kaschak, M. P. (2002). Grounding language in action. Psychonomic Bulletin 88 Review, 9(3), 558-565.

Goldin-Meadow, S. (2003). Hearing gesture: How our hands help us think. Cambridge, MA: The Belknap Press.

Goldin-Meadow, S., Nusbaum, H., Kelly, S. D., \& Wagnet, S. (2001). Explaining math: Gesturing lightens the load. Psychological Science, 12(6), 516-522.

Goodwin, C. (2000). Gesture, aphasia, and interaction. In D. McNeill (Ed.), Language and gesture (pp. 84-98). Cambridge: Cambridge University Press.

Gullberg, M. (1998). Gesture as a communication strategy in second language discourse. A study of learners of French and Swedish. Lund: Lund University Press.

Gullberg, M. (1999). Communication strategies, gestures, and grammar. Acquisition et Interaction en Langue Etrangère, Numéro spécial: Eurosla8. A selection of papers (ed. Perdue, C. 8 Lambert, M.) (2), 61-71.

Gullberg, M. (2003). Gestures, referents, and anaphoric linkage in learnet varieties. In C. Dimroth \& M. Starten (Eds.), Information structure, linguistic structure and the dynamics of language acquisition (pp. 311-328). Amsterdam: John Benjamins.

Gullberg, M. (2006a). Handling discourse: Gestures, reference tracking, and communication strategies in early L2. Language Learning, 56(1), 155-196.

Gullberg, M. (2006b). Some reasons for studying gesture and second language acquisition (Hommage à Adam Kendon). International Review of Applied Linguistics, 44(2), 103-124.

Gullberg, M. (forthcoming). What learners mean. What gestures reveal about semantic teorganisation of placement verbs in advanced L2.

Gullberg, M. (submitted). Language-specific encoding of placement events in gestures. In E. Pederson \& J. Bohnemeyer (Eds.), Event representations in language and cognition. Cambridge: Cambridge University Press.

Gumperz, J. J., \& Levinson, S. C. (1996). Introduction: Linguistic relativity re-examined. In J. J. Gumperz \& S. C. Levinson (Eds.), Rethinking linguistic relativity (pp. 1-18). Cambridge: Cambridge University Press.

Harris, T. (2003). Listening with your eyes: The importance of speech-related gestures in the language classroom. Foreign Language Annals, 36(2), 180-187.

Hauge, E. (2000). The role of gesture in British ELT in a university setting. Unpublished PhD diss., University of Southampton, Southampton.

Haviland, J. B. (1993). Anchoring, iconicity and orientation in Guugu Yimithirt pointing gestures. Journal of Linguistic Anthropology, 3(1), 3-45.

Haviland, J. B. (1996). Projections, transpositions, and relativity. In J. J. Gumperz \& S. C. Levinson (Eds.), Rethinking linguistic relativity (pp. 271-323). Cambridge; Cambridge University Press.

Hendriks, H. (2003). Using nouns for reference maintenance: a seeming contradiction in L2 discourse. In A. G. Ramat (Ed.), Typology and second language acquisition (pp. 291-326). Berlin: Mouton.

Henzl, V. M. (1979). Foreigner talk in the classroom. International Review of Applied Linguistics, 17(2), 159-167.

Holler, J., \& Beattie, G. (2003). Pragmatic aspects of tepresentational gestures. Do 
speakers use them to clarify verbal ambiguity for the listener? Gesture, 3(2), $127-154$.

Hostetter, A. B., \& Alibali, M. W. (2004). On the tip of the mind: Gesture as a key to conceptualization. In K. D. Forbus, D. Gentner \& T. Regier (Eds.), The 26th Annual Conference of the Cognitive Science Society (pp. 589-594). Chicago: Cognitive Science Society.

Iverson, J. M., Capirci, O., Longobardi, E., \& Caselli, M. C. (1999). Gesturing in mother-child interactions. Cognitive Development, 14(1), 57-75.

Jarvis, S. (2000). Methodological rigor in the study of transfer: Identifying L1 influence in the interlanguage lexicon. Language Learning, 50(2), 245-309.

Jenkins, S., \& Parra, I. (2003). Multiple layers of meaning in an oral proficiency test: The complementary roles of nonverbal, paralinguistic, and verbal behaviors in assessment decisions. Modern Language Journal, 87(1), 90-107.

Jungheim, N. O. (1991). A study on the classtoom acquisition of gestures in Japan. Ryutsukeizaidaigaku Ronshu, 26(2), 61-68.

Jungheim, N. O. (2001). The unspoken element of communicative competence: Evaluating language learners' nonverbal behavior. In T. Hudson \& J. D. Brown (Eds.), A focus on language test development: Expanding the language proficiency construct across a variety of tests (Vol. 21, pp. 1-34). Honolulu: University of Hawai' $i$, Second Language Teaching and Curriculum Center.

Jungheim, N. O. (2006). Learner and native speaker perspectives on a culturallyspecific Japanese refusal gesture. International Review of Applied Linguistics, $44(2), 125-142$.

Kellerman, E. (1995). Crosslinguistic influence: Transfer to nowhere? Annual Review of Applied Linguistics, 15, 125-150.

Kellerman, E., \& Van Hoof, A.-M. (2003). Manual accents. International Review of Applied Linguistics, 41(3), 251-269.

Kellerman, S. (1992). "I see what you mean": The role of kinesic behaviour in listening and implications for foreign and second language learning. Applied Linguistics, 13(3), 239-257.

Kelly, S. D., Kravitz, C., \& Hopkins, M. (2004). Neural correlates of bimodal speech and gesture comprehension. Brain and Language, 89(1), 253-260.

Kendon, A. (1972). Some relationships between body motion and speech: An analysis of an example. In A. W. Siegman \& B. Pope (Eds.), Studies in dyadic communication (pp. 177-210). New York: Pergamon.

Kendon, A. (1988). How gestures can become like words. In F. Poyatos (Ed.), Crosscultural perspectives in nonverbal communication (pp. 131-141). Totonto: Hogrefe.

Kendon, A. (1994). Do gestures communicate?: A review. Research on Language and Social Interaction, 27(3), 175-200.

Kendon, A. (2002). Some uses of the head shake. Gesture, 2(2), 147-182.

Kendon, A. (2004). Gesture. Visible action as utterancè. Cambridge: Cambridge University Press.

Kida, T. (2005). Appropriation du geste par les étrangers: Le cas d'étudiants japonais apprenant le français. Unpublished PhD diss., Université de Provence (AixMarseille I), Aix-en-Provence.

Kita, S. (1993). Language and thought interface: A study of spontaneous gestures and Japanese mimetics. Unpublished $\mathrm{PhD}$ diss., University of Chicago, Chicago. 
Kita, S., \& Özyürek, A. (2003). What does cross-linguistic variation in semantic coordination of speech and gesture reveal?: Evidence for an interface representation of spatial thinking and speaking. Journal of Memory and Language, 48(1), $16-32$.

Kita, S., Van Gijn, l., \& Van der Hulst, H. (1998). Movement phases in signs and co-speech gestures, and their transcription by human coders. In I. Wachsmuth \& M. Fröhlich (Eds.), Gesture and sign language in human-computer interaction, pp. 23-35. Berlin: Springer.

Klatzky, R. L., Pellegrino, J. W., McCloskey, B. P., \& Doherty, S. (1989). Can you squeeze a tomato? The role of motor representations in semantic sensibility judgments. Journal of Memory and Language, 28(1), 56-77.

Klein, W., \& Perdue, C. (1997). The basic variety (or: Couldn't natural languages be much simpler?). Second Language Research, 13(4), 301-347.

Koschmann, T., \& LeBaron, C. (2002). Learner articulation as interactional achievement: Studying the conversation of gesture. Cognition $\mathbb{F}^{2}$ Instruction, 20(2), 249-282.

Krashen, S. D. (1994). The input hypothesis and its rivals. In N. C. Ellis (Ed.), Implicit and explicit learning of languages (pp. 45-78). London: Academic Press.

Krauss, R. K., Chen, Y., \& Gottesman, R. F. (2000). Lexical gestures and lexical access: a process model. In D. McNeill (Ed,), Language and gesture (pp. 261-283). Cambridge: Cambridge University Press.

- Krauss, R. M., Chen, Y., \& Chawla, P. (1996). Nonverbal behavior and nonverbal communication: What do conversational hand gestures tell us? Advances in Experimental Social Psychology, 28, 389-450.

Lakoff, G., \& Johnson, M. (1980). Metaphors we live by. Chicago: Chicago University Press.

Langton, S. R. H., Q’Malley, C., \& Bruce, V. (1996). Actions speak no louder than words: Symmetrical cross-modal interference effects in the processing of verbal and gestural information. Journal of Experimental Psychology: Human Perception and Performance, 22(6), 1,357-1,375.

Lazaraton, A. (2004). Gesture and speech in the vocabulary explanations of one ESL teacher: A microanalytic inquiry. Language Learning, 54(1), 79-117.

Levelt, W. J. M., Richardson, G., \& La Heij, W. (1985). Pointing and voicing in deictic expressions. Journal of Memory and Language, 24(2), 133-164.

Levelt, W. J. M., Roelofs, A., \& Meyer, A. S. (1999). A theory of lexical access in speech production. Behavioral and Brain Sciences, 22(1), 1-37(75).

Levinson, S. C. (2003). Space in language and cognition. Explorations in cognitive diversity. Cambridge: Cambridge University Press.

Levy, E. T., \& McNeill, D. (1992). Speech, gesture, and discourse. Discourse Processes, 15(3), 277-301.

Lott, P. (1999). Gesture and ophasia. Bern: Peter Lang.

Mayberry, R. I., \& Jaques, J. (2000). Gesture production during stuttered speech: Insights into the nature of gesture-speech integration. In D. McNeill (Ed.), Language and gesture (pp. 199-214). Cambridge: Cambrịdge University Press.

Mayberry, R. I., \& Nicoladis, E. (2000). Gesture reflects language development: Evidence from bilingual children. Current Directions in Psychological Science, $9(6), 192-196$. 
Maynard, S. K. (1990). Conversation management in contrast: Listener tesponse in Japanese and American English. Journal of Pragmatics, 14, 397-412.

McCafferty, S. G. (1998). Nonverbal expression and L2 private speech. Applied Linguistics, 19(1), 73-96.

McCafferty, S. G. (2002). Gesture and creating zones of proximal development for second language learning. Modern Language Journal, 86(2), 192-203.

McCafferty, S. G. (2004). Space for cognition: Gesture and second language learning. International Journal of Applied Linguistics, 14(1), 148-165.

McCafferty, S. G. (2006). Gesture and the materialization of second language prosody. International Review of Applied Linguistics, 44(2), 195-207.

McClave, E. (2000). Linguistic functions of head movements in the context of speech. Journal of Pragmatics, 32(7), 855-878.

McNeill, D. (1985). So you think gestures are nonverbal? Psychological Review, 92(3), 271-295.

McNeill, D. (1992). Hand and mind. What the hands reveal about thought. Chicago: Chicago University Press.

McNeill, D. (2000). Introduction. In D. McNeill (Ed.), Language and gesture (pp. 1-10). Cambridge: Cambridge University Press.

McNeill, D. (2005). Gesture and thought. Chicago: University of Chicago Press.

McNeill, D., \& Duncan, S. D. (2000). Growth points in thinking-for-speaking. In D. McNeill (Ed.), Language and gesture (pp. 141-161). Cambridge: Cambridge University Press.

McNeill, D., Levy, E. T., \& Cassell, J. (1993). Abstract deixis. Semiotica, 95(1/2); 5-19.

Melinger, A., \& Levelt, W. J. M. (2004). Gesture and the communicative intention of the speaker. Gesture, 4(2), 119-141.

Mohan, B., \& Helmer, S. (1988). Context and second language development: Preschoolers' comprehension of gestures. Applied Linguistics, 9(3), 275-292.

Motris, D., Collett, P., Marsh, P., \& O'Shaughnessy, M. (1979). Gestures, their origins and distribution. London: Cape.

Müller, C. (1994). Semantic structure of motional gestures and lexicalization patterns in Spanish and German descriptions of motion-events. In K. Beals, J. M. Denton, R. Knippen, L. Melnar, H. Suzuki, \& E. Zeinfeld (Eds.), Papers from the Annual Regional Meeting of the Chicago Linguistic Society. The main session (Vol. 30, pp. 281-295). Chicago, IL: Chicago Linguistic Society.

Musumeci, D. M. (1989). The ability of second language learners to assign tense at the sentence Level: A crosslinguistic study. Unpublished Ph.D diss., University of Illinois at Urbana-Champaign.

Negueruela, E., Lantolf, J. P., Rehn Jordan, S., \& Gelabert, J. (2004). The "private function" of gesture in second language speaking activity: A study of motion verbs and gesturing in English and Spanish. International Journal of Applied Linguistics, 14(1), 113-147.

Núñez, R. E., \& Sweetser, E. (2006). With the future behind them: Convergent evidence from Aymara language and gesture in the crosslinguistic comparison of spatial construals of time. Cognitive Science, 30(3), 401-450.

O'Neill, D. K., Topolovec, J., \& Stern-Cavalcante, W. (2002). Feeling sponginess: The importance of descriptive gestures in 2 - and 3-year-old children's acquisition of adjectives. Journal of Cognition and Development, 3(3), 243-277. 
Odlin, T. (2005). Crosslinguistic influence and conceptual transfer: What are the concepts? Annual Review of Applied Linguistics, 25, 3-25.

Özyuizek, A. (2002a). Do speakers design their cospeech gestures for their addressees? The effects of addressee location on representational gestures. Journal of Memory and Language, 46, 688-704.

Özyiurek, A. (2002b). Speech-language relationship across languages and in second language learners: Implications for spatial thinking and speaking. In B. Skarabela (Ed.), BUCLD Proceedings (Vol. 26, pp. 500-509). Somerville, MA: Cascadilla Press.

Özyürek, A., Kita, S., Allen, S. E. M., Furman, R., \& Brown, A. (2005). How does linguistic framing of events influence co-speech gestures? Insights from crosslinguistic variations and similarities. Gesture, 5(1/2), 219-240.

Pavlenko, A., \& Jarvis, S. (2002). Bidirectional transfer. Applied Linguistics, 23(2), $190-214$.

Payrató, L. (1993). A pragmatic view on autonomous gestures: A first repertoire of Catalan emblems. Journal of Pragmatics, 20(3), 193-216.

Poyatos, F. (2002). Nonverbal communication across disciplines Amsterdam: John Benjamins.

Rizzolatti, G., \& Craighero, L. (2004). The mitrot-neuron system. Annual Review of Neuroscience, 27(1), 169-192.

Rogers, W. T. (1978). The contribution of kinesic illustrators toward the comprehension of verbal behaviot within utterances. Human Communication Research, 5(1), 54-62.

Rose, M. L. (2006). The utility of arm and hand gesture in the treatment of aphasia. Advances in Speech-Language Pathology, 8(2), 92-109.

Roth, W.-M. (2003). From epistemic (ergotic) actions to scientific discourse: The bridging function of gestures. Pragmatics and Cognition, 11(1), 141-170.

Sapit, E. A. (1951). The unconscious patterning of behavior in society. In D. G. Mandelbaum (Ed.), Selected writings of Edward Sapir in Language, Culture, and Personality (pp. 544-559/556). Berkeley: University of California Press.

Schegloff, E. A. (1984). On some gestures' relation to talk. In J. M. Atkinson \& J. Heritage (Eds.), Structures of social action (pp. 266-296). Cambridge: Cambridge University Press.

Schmitt, J.C. (1991). The rationale of gestures in the West: Third to thirteenth centuries. In J. Bremmer \& H. Roodenburg (Eds.), A cultural history of gesture (pp. 59-70). Ithaca, NY: Cornell University Press.

Seyfeddinipur, M. (2006). Disfluency: Interrupting speech and gesture. Unpublished PhD diss., Radboud University, Nijmegen.

Sherman, J., \& Nicoladis, E. (2004). Gestures by advanced Spanish-English second-language learners. Gesture, 4(2), 143-156.

Sherzer, J. (1972). Verbal and nonverbal deixis: The pointed lip gesture among the San Blas Cuna. Language and Society, 2(1), 117-131.

Singer, M. A., \& Goldin-Meadow, S. (2005), Children learn when their teacher's gestures and speech differ. Psychological Science, 16(2), 85-89.

Slama-Cazacu, T. (1976). Nonverbal components in message sequence: "Mixed syntax". In W. C. McCormack \& S. A. Wurm (Eds.), Language and man: Anthropological issues (pp. 217-227). The Hague: Mouton.

Slobin, D. I. (1996). From "thought and language" to "thinking for speaking". In 
J. J. Gumperz \& S. C. Levinson (Eds.), Rethinking linguistic relativity (pp. 70-96). Cambridge: Cambridge University Press.

Slobin, D. I. (2004). How people move. Discourse effects of linguistic typology. In C. L. Moder \& A. Martinovic-Zic (Eds.), Discourse across languages and cultures (pp. 195-210). Amsterdam: John Benjamins.

Stam, G. (2006). Thinking for Speaking about motion: L1 and L2 speech and gesture. International Review of Applied Linguistics, 44(2), 143-169.

Stokoe, W. C. (1980). Sign language structure. Annual Review of Anthropology, 9, 365-390.

Streeck, J., \& Hartege, U. (1992). Previews: Gestures at the transition place. In P. Auer \& A. di Luzio (Eds.), The contextualization of language (pp. 135-157). Amsterdam: John Benjamins.

Sueyoshi, A., \& Hardison, D. M. (2005). The role of gestures and facial cues in second language listening comprehension. Language Leaming, 55(4), 661-699.

Swain, M. (2000). The output hypothesis and beyond: Mediating acquisition through collaborative dialogue. In J. P. Lantolf ' $(\mathrm{Ed}$.), Sociocultural theory and second language learning (pp. 97-114). Oxford: Oxford University Press.

Talmy, L. (1985). Lexicalization patterns: Semantic structure in lexical forms. In T. Shopen (Ed.), Language typology and syntactic description (Vol. 3, pp. 57-149). Cambridge: Cambridge University Press.

Taranger, M.C., \& Coupier, C. (1984). Recherche sur l'acquisition des langues secondes. Approche du gestuel. Paper presented at the Acquisition d'une langue étrangère. Perspectives et recherches, Aix-en-Provence.

Tellier, M. (2006). L'impact du géste pédagogique sur l'enseignement/apprentissage des langues étrangères: Etude sur des enfants de 5 ans. Unpublished PhD diss., Université Paris VII-Denis Diderot, Paris.

Valenzeno, L., Alibali, M. W., \& Klatzky, R. (2002). Teachers' gestures facilitate students' learning: A lesson in symmetry. Contemporary Educational Psychology, $28,187-204$.

Von Raffler-Engel, W. (1980). Kinesics and paralinguistics: A neglected factor in second language research and teaching. Canadian Modern Language Review, $36(2), 225-237$.

Von Stutterheim, C., \& Klein, W. (2002). Quaestio and L-perspectivation. In C. F. Graumann \& W. Kallmeyer (Eds.), Perspective and perspectivation in discourse (pp. 59-88). Amsterdam: John Benjamins.

Wieselman Schulman, B. (2004). A crosslinguistic investigation of the speech-gesture relationship in motion event descriptions. Unpublished $\mathrm{PhD}$ diss., University of Chicago, Chicago.

Wilkins, D. P. (2003). Why pointing with the index finger is not a universal (in socio-cultural and semiotic terms). In S. Kita (Ed.), Pointing: Where language, culture, and cognition meet (pp. 171-215). Mahwah, NJ: Erlbaum.

Willems, R. M., Özyürek, A., \& Hagoort, P. (2005). The comprehension of gesture and speech. Journal of Cognitive Neuroscience, 17 (Supplement), 231.

Wolfgang, A., \& Wolofsky, Z. (1991). The ability of new Canadians to decode gestures generated by Canadians of Anglo-Celtic backgrounds. International Journal of Intercultural Relations, 15(1), 47-64.

Wu, Y. C., \& Coulson, S. (2005). Meaningful gestures: Electrophysiological indices of iconic gesture comprehension. Psychophysiology, 42(6), 654-667. 
Yoshioka, K. (2005). Linguistic and gestural introduction and tracking of referents in $L 1$ and L2 discourse. Unpublished PhD diss., Rijksuniversiteit Groningen, Groningen.

Yoshioka, K., \& Kellerman, E. (2006). Gestural introduction of Ground teference in L2 narrative discourse. International Review of Applied Linguistics, 44(2), 171-193. 


\section{HANDBOOK OF COGNITIVE LINGUISTICS AND SECOND LANGUAGE ACQUISITION}

Edited by

Peter Robinson

Aoyama Gakuin University, Japan

and

Nick C. Ellis

University of Michigan, U.S.A. 
First published 2008

by Routledge

270 Madison Ave, New York, NY 10016

Simultaneously published in the UK by Routledge

2 Park Square, Milton Park, Abingdon, Oxon OX14 4RN

Routledge is an imprint of the Taylor \& Francis Group, an informa business

\section{(C) 2008 Taylor \& Francis}

Typeset in Goudy by

RefineCatcb Limited, Bungay, Suffolk

Ptinted and bound in the United States of America on acid-free paper by Sheridan Books, Inc.

All tights reserved. No part of this book may be reprinted or reproduced or utilized in any form or by any electronic, mechanical, or other means, now known or hezeafter invented, including photocopying and recotding, or in any information storage or retrieval system, without permission in writing from the publishers.

Trademark Notice: Product or corporate names may be trademarks or registered trademarks, and are used only for identification and explanation without intent to infringe.

Library of Congress Cataloging in Publication Data

Robinson, Peter

Handbook of cognitive linguistics and second language acquisition / by Peter Robinson and Nick C. Ellis:

$$
\text { p. cm. }
$$

Includes index.

ISBN 978-0-8058-535I-3-ISBN 978-0-8058-5352-0

ISBN 978-0-203-9.3856-0

1. Cognitive grammar. 2 . Second language acquisition. 3. Language and languages - Study and teaching. I. Ellis, Nick $C$. II. Tit Ie.

P165.R63 2008

$$
410-\mathrm{dc} 22
$$

2007026713

ISBN10: 0-805-85351-0 (hbk)

ISBN 10: 0-805-85352-9 (pbk)

ISBN10: 0-203-93856-9 (ebk)

ISBN13: 978-0-805-8535t-3 (hbk)

ISBN 13: 978-0-805-85352-0 (pbk)

ISBNI3: 978-0 203-93856-0 (ebk) 


\section{CONTENTS}

List of figures viii

List of tables ix

List of contributors $\quad \mathrm{x}$

PART I

Introduction $\quad 1$

1 An introduction to Cognitive Linguistics, Second Language Acquisition, and language instruction 3 NICK C. ELLIS AND PETER ROBINSON

PART II

Cognitive Linguistics and cognition 25

2 Aspects of attention in language $\quad 27$ LEONARD TALMY

3 Prototypes in Cognitive Linguistics 39 JOHN R. TAYLOR

4. Cognitive Grammar as a basis for language instruction 66 RONALD W. LANGACKER

5 Word Grammar, Cognitive Linguistics, and second language learning and teaching RICHARD HUDSON 
6 Spatial language learning and the functional geometric framework

KENNY R. COVENTRY AND PEDRO GUIJARRO-FUENTES

7 Language without grammar

WILLIAM O'GRADY

8 Children's first language acquistion from a usage-based perspective

ELENA LIEVEN AND MICHAEL TOMASELLO

9 Construction learning and Second Language Acquisition ADELE E. GOLDBERG AND DEVIN CASENHISER

10 Usage-based grammar and Second Language Acquisition JOAN BYBEE

PART III

Cognitive Linguistics, Second Language Acquisition, and L2 instruction

11 Learning to talk about motion in a foreign language TERESA CADIERNO

12 Gestures and Second Language Acquisition MARIANNE GULLBERG

13 Conceptual transfer and meaning extensions TERENCE ODLIN

14 A unified model BRIAN MACWHINNEY

15 Usage-based and form-focused language acquisition: The associative learning of constructions, learned attention, and the limited $\mathrm{L} 2$ endstate NICK C. ELLIS 
16 Corpus-based methods in analyses of Second Language Acquisition data

STEFAN TH. GRIES

17 Teaching construal: Cognitive Pedagogical Grammar MICHEL ACHARD

18 Cognitive Linguistics and second language instruction 456 ANDREA TYLER

19 Conclusion: Cognitive Linguistics, Second Language Acquisition and L2 instruction-issues for research PETER ROBINSON AND NICK C. ELLIS

Author index 


\section{FIGURES}

3.1 A network for allophones of the phoneme $/ \mathrm{t} / \mathrm{s}$

4.1 Profiling of things and relationships 69

$\begin{array}{lll}4.2 & \text { Contrasting profiles } & 74\end{array}$

4.3 A constructional schema 75

5.1 A tiny network centered on the adjective FAST 93

5.2 An English speaker learns the French word chat 95

5.3 Loves inherits its subject properties from Verb 97

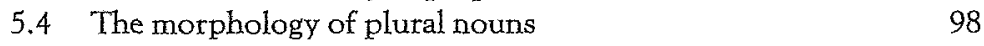

5.5 Subject-auxiliary inversion in a network 99

5.6 Three languages that I know about and the words I

5.7 What I know about the speaker of two English words 102

5.8 An abstract network showing three correlated properties 106

5.9 A new node carries the default properties 107

6.1 Examples of scenes used in video experiments manipulating geometry and location control 118

6.2 Examples of scenes showing three positions of a shield 121

6.3 Visuo-spatial scenes illustrating "the bird is in the dish" versus "the bird is on the dish" 133

14.1 Part of speech organization in the DevLex network 343

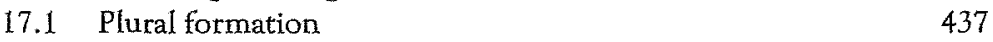

18.1 English modal verbs 473

18.2 Wilcoxon Signed Ranks test for "Hedges" in Drafts 1 and 2 of feedback and minimal feedback groups

18.3 Wilcoxon Signed Ranks test for "Boosters" in Drafts 1 and 2 of EL and USLD groups 


\section{TABLES}

9.1 15 mothers' most frequent verb and number of verbs types

15.1 A contingency table showing four possible combinations of events

15.2 The design and outcome of Chapman \& Robbins' (1990) cue interaction experiment illustrating "blocking" 386

18.1 Wilcoxon Signed Ranks test for minimal feedback group 479

18.2 Wilcoxon Signed Ranks test for feedback group 479

18.3 Comparison of modal verb usage before and after modal lesson

18.4 Correct modal usage by individual subject 483 